\title{
GÉNERO: CONTRIBUTOS PARA UMA COMPREENSÃO EFETIVA DAS MUDANÇAS
}

\author{
Moisés de Lemos Martins', Maria Manuel Baptista², Zara Pinto-Coelho³ \& Sara Maia4
}

Nos últimos 20 anos, as relações de género e a forma como são experienciadas, representadas e consubstanciadas em práticas, sofreram mudanças profundas. Urge compreender este processo de forma mais aprofundada e efetiva, particularmente no que diz respeito às dinâmicas de poder e de controlo envolvidas, e ao espaço dos países de expressão portuguesa.

Tendo como pano de fundo estas reconfigurações e interesses, a Revista Lusófona de Estudos Culturais reúne no seu $5^{\circ}$ número contribuições de investigadores em início de carreira e investigadores consagrados de várias partes do mundo (Grã-Bretanha, Estados Unidos da América, Brasil e Portugal) e proporciona aos leitores portugueses a possibilidade de lerem na sua língua materna os trabalhos de Raewyn Connell, Jasbir Puar e Sue Thornham.

O conjunto de artigos que integram este número, procura concorrer, numa lógica inter ou transdisciplinar, para uma compreensão aprofundada e crítica das mudanças ocorridas em diversos domínios da sociedade com implicações nas relações e nas identidades de género. Os participantes trabalham com diferentes quadros teóricos e visam a compreensão de questões diversas relacionadas com os domínios da maternidade, das relações afetivas e sexuais, do envelhecimento, do ativismo social, da ciência e da academia, da economia e das políticas públicas.

A iniciar o volume, Sue Thornham, a propósito do filme Precisamos de falar sobre Kevin (2011), realizado por Lynne Ramsay, uma realizadora escocesa cuja obra tem integrado um interesse pela figura da mãe, traz para a discussão o "novo mamaísmo" que surgiu nos anos 90 nos Estados Unidos da América. Segundo a académica da universidade de Sussex, o filme de Ramsay constitui uma crítica ao discurso pós-feminista de celebração de um novo modo de ser mãe a tempo inteiro. Neste discurso, a maternidade é retratada como uma escolha feita por uma mulher liberada e esclarecida e como parte integrante da realização pessoal feminina. Situando a sua discussão no quadro do cinema de resistência feminista e dos melodramas maternais, a autora defende que no filme de Ramsay a díade mãe-filho, ao contrário de filmes anteriores, é apresentada pelos olhos da mãe. Precisamos de falar sobre Kevin leva-nos para um mundo cujos termos e

\footnotetext{
' Centro de Estudos de Comunicação e Sociedade - Universidade do Minho. E-mail: moisesm@ics.uminho.pt; moiseslmartins@gmail.com

${ }^{2}$ Centro de Línguas Literaturas e Culturas - Universidade de Aveiro. E-mail: mbaptista@ua.pt

${ }^{3}$ Centro de Estudos de Comunicação e Sociedade - Universidade do Minho. E-mail: zara@ics.uminho.pt

${ }^{4}$ Centro de Estudos de Comunicação e Sociedade - Universidade do Minho. E-mail: saravmaia@ua.pt
} 
limites são ditados pelo filho, num horizonte cultural que insiste na possibilidade de escolha, ao mesmo tempo que demonstra a impossibilidade da mesma. Sue defende que o filme coloca-nos numa posição de sujeito armadilhada, de violência cúmplice, para a qual parece não haver nem saída, nem possibilidade de redenção.

Ainda sobre o tema da maternidade, Aline Gonçalves e Celsi Silvestrin, a propósito da mobilização, ocorrida em 2012, de um conjunto de mulheres brasileiras em defesa do parto domiciliar, mostram como o uso combinado dos novos média e dos média tradicionais foi fundamental para ampliar a discussão e visibilidade social do tema, e para impulsionar uma ação coletiva em torno do mesmo. Situando a sua análise no papel da comunicação e dos atores coletivos na sociedade, as investigadoras apresentam também elementos que ajudam a compreender as razões que levaram mulheres brasileiras a contestar o modelo de assistência obstétrica vigente, a defender os direitos de escolha e de autonomia das mulheres em relação ao parto e o acesso a um atendimento humanizado.

A discussão em torno da maternidade continua no artigo de Claúdia Alvarez. A Professora Associada da Universidade Lusófona de Lisboa organiza o seu artigo em torno das novas configurações de maternidade decorrentes do recurso a técnicas de Procriação Medicamente Assistida. Motivada por uma análise dos entendimentos do conceito de maternidade presentes na cobertura noticiosa da Procriação Medicamente Assistida por parte do jornal Público nos anos 2008 e 2009, Claúdia destaca que os esforços de contenção da deriva de significados em que se encontra atualmente o conceito de maternidade são inglórios, uma vez que o progresso constante da técnica torna cada mais evidente o fosso entre o social e o biológico. O que até há pouco tempo era relativamente consensual, tornou-se, segundo a autora, particularmente controverso, mesmo no seio da discussão feminista, com umas a celebrar a primazia do social sobre o biológico e outras a defender a vinculação biológica entre mãe e filho. A investigadora conclui que a cobertura do assunto no jornal Público manifesta uma clara tendência para inserir estas novas realidades no modelo médico tradicional das relações maternais, priorizando a transmissão de um património genético em detrimento da dimensão "educar/criar um filho".

Mirian Goldenberg, no artigo intitulado "Casamentos invertidos: acusações e preconceitos em arranjos conjugais desviantes", procura compreender as razões pelas quais, numa cultura e sociedade em que o corpo jovem é um capital e o casamento com homens mais novos visto como desviante, algumas mulheres preferem maridos mais jovens e alguns homens mulheres mais velhas. Tomando como base os dados da pesquisa "Corpo, envelhecimento e felicidade", analisa os discursos de mulheres e homens sobre casamentos nos quais as mulheres são mais velhas do que os seus maridos. A académica propõe a palavra "salvação" como condensador descritivo principal destes discursos: eles salvaram as mulheres da morte social e elas salvaram os homens da morte precoce, e ambos batalham no sentido de preservar o seu tão estimado porto de abrigo. Mirian conclui interrogando-se por que razões muitas mulheres e homens brasileiros continuam a fortalecer o tabu da idade e a sublinhar a juventude como principal moeda de troca nas relações afetivas e sexuais. Num contexto em que o crescimento de arranjos conjugais considerados desviantes não para de crescer, os testemunhos dessas 
experiências parecem reveladores da existência de um maior grau de satisfação nesses arranjos do que em relacionamentos socialmente aceites.

Mantendo-nos no contexto brasileiro, o artigo de Tânia Montoro e de Maria Luiza Mendonça, a propósito da novela exibida pela Rede Globo no horário "nobre", das 21 horas, Babilónia, trazem para a reflexão a articulação entre o envelhecimento e o lesbianismo, e os seus efeitos de poder e de exclusão. Procuram compreender em particular as razões do debate intenso e polarizado das manifestações públicas nas redes sociais em torno do casal de lésbicas de idade madura existente na trama da novela. As investigadoras sublinham as contradições que atravessam a sociedade brasileira atual, onde a par das transformações ocorridas em instituições tradicionais, como é o caso da família, e de discursos progressistas a favor de categorias e grupos minoritários, por exemplo no campo legislativo, persistem ainda a intolerância e os preconceitos contra mulheres que reúnem dois tipos de estigma: a velhice e o lesbianismo.

Visando compreender a influência do sexo nos processos de luto e na capacidade de adaptação à perda, Jenny Sousa e Maria Manuel Baptista apresentam os resultados de um estudo empírico desenvolvido num contexto de viuvez e de institucionalização permanente. A investigação revela diferenças entre os discursos das viúvas e dos viúvos, base a partir da qual as autoras sublinham que a perda e os aspetos que envolvem a superação da mesma são influenciados pelos papéis de género que condicionaram as experiências e as formas de sociabilidade do casal. As autoras fecham o artigo com uma recomendação às estrutura residenciais no sentido de as mesmas fornecerem diferentes estratégias de apoio na superação do luto, adequadas e coerentes com os universo sociais e culturais das viúvas e dos viúvos.

A abrir o tema do género e das políticas públicas, temos o artigo intitulado "As mulheres na mobilidade académica internacional: uma caraterização das pesquisadoras brasileiras na Universidade do Minho" de Sônia Cerqueira e Rita Ribeiro. Neste texto as autoras apresentam quem são as mulheres inseridas na mobilidade internacional e o que procuram nestas trajetórias, quais são as suas principais motivações na escolha da universidade e do país de acolhimento e quais os significados e sentidos que atribuem à mobilidade. Ancoram a análise desta realidade no debate sobre o crescimento da participação feminina na ciência e na academia no Brasil, e as desigualdades de género que persistem ainda naqueles campos e diminuem as oportunidades das mulheres ocuparem certas posições na hierarquia profissional e em determinadas áreas do saber. Referem ainda como as desigualdades de género se manifestam no intercâmbio internacional, destacando em particular os obstáculos derivados da colagem cultural das mulheres à esfera da reprodução (e às expetativas daí decorrentes de serem mais propensas à prestação do cuidado, nomeadamente no seio das famílias). As investigadoras caraterizam a mobilidade em análise como desviante (semi-periférica) face às formas hegemónicas de mobilidade académica, e como uma tentativa de construção de novas trajetórias de ação na ciência, movida pela necessidade de visibilidade, de um maior reconhecimento profissional e por um desejo de acolhimento e de integração social.

Juliana Souza questiona no seu artigo a não inclusão de políticas públicas que contemplem as relações de género, no Portugal da crise financeira atual. Explorando a 
hipótese de o impacto da recessão financeira variar segundo a exclusão ou a incorporação de modelos de gestão baseados em políticas públicas que compreendam as relações de género, a autora assinala alguns dos principais impactos da recessão no quotidiano das mulheres em Portugal. Realça em particular duas questões: o modo como a ausência de políticas públicas para a igualdade de género se tornou determinante para o agravamento da crise social em anos de austeridade; e como o diálogo entre o modelo neoliberal, a retórica pós-feminista do consumo e da meritocracia e o incentivo mediático para que as mulheres regressem ao papel de dona de casa como meio de combate à crise conflui para estreitar ainda mais as posições de sujeito das mulheres portuguesas, acentuando a sua subordinação e opressão, ao mesmo tempo que pode favorecer um retrocesso ideológico.

No quadro dos debates liberais sobre discursos de direitos, e do sujeito baseado em direitos, Jasbir Puar, Professora Associada da Universidade Rutgers, Nova Jérsia, Estados Unidos da América, traz para o debate o surgimento dos movimentos gays e lésbicos e mostra como a sexualidade se tornou fundamental para a articulação dos cidadãos plenos em áreas como o género, a classe e a raça, tanto em termos nacionais como transnacionais. A investigadora sublinha que é necessário olhar para as consequências não progressistas da legislação progressista relativa a modos de conduta corporal que desafiam os parâmetros da identidade. Chamando a terreno o seu trabalho sobre homonacionalismo, destaca a relevância dos discursos sobre direitos sexuais e da narrativa de "lavagem cor-de-rosa" para legitimar a ocupação da Palestina por Israel. Jasbir afirma que o âmago do discurso de "lavagem cor-de-rosa" não é a identidade sexual, mas a regulação da identidade num mundo crescentemente homonacionalista — isto é, - um mundo que avalia a pertença nacional com base no tratamento dos seus homossexuais. Conclui propondo que pensemos a sexualidade não como uma identidade, mas mosaicos de sensações, afetos e forças. A viralidade desta noção, diz-nos a autora, tem o potencial de destabilizar não só noções humanistas dos sujeitos da sexualidade, como também a organização política que procura resistir aos discursos jurídicos instituídos com o objetivo de nomear e controlar estes sujeitos de sexualidade.

A coleção de artigos publicados neste número 5 da Revista Lusófona de Estudos Culturais encerra com o contributo de Raewyn Connell, Professora Emérita da Universidade de Sydney. A investigadora propõe-se devolver os corpos ao debate sobre género, no quadro de um mundo novo que descreve como instável, ameaçador e de capitalismo desregulado, onde os corpos são colonizados e minados tendo em vista o lucro. Raewyn sublinha que a natureza genderizada da economia mundial e do sistema político contemporâneo deriva de uma longa história de relações de poder de género, inseridas nas estruturas institucionais das sociedades imperiais e pós-coloniais, que é também a história de uma luta. Discute em seguida a complexidade dos efeitos de género do neoliberalismo e a diversidade dos mesmos através do globo. Termina o artigo fazendo um apelo à criação de "feminismos impuros", à mobilização nas periferias e à necessidade de ligar as diferentes experiências feministas e as diferentes abordagens conceptuais de todo o mundo no sentido de construir, a uma escala mundial, uma compreensão mais adequada do corpo, da corporificação, do poder e da resistência. 
A secção Vária inclui um artigo de Moisés de Lemos Martins, Professor Catedrático da Universidade do Minho. Neste texto propõe que encaremos os Estudos Culturais como as novas Humanidades, apresentando para o efeito argumentos vários. Estudar a cultura significa para o autor estudar o humano, com um sensibilidade particular pelo que o humano tem de vertiginoso e no quadro de um compromisso com o atual e o contemporâneo. Problematiza em particular o papel que a técnica tem na redefinição e na delimitação do humano, vendo nela a realização da razão como controlo e, simultaneamente, a modelação da nossa sensibilidade e emotividade. Moisés Martins entende que o enfoque no eixo de sentido técnico-estético, que exprime uma modernidade que diz a crise desta época, tem manifestos efeitos emancipadores: integra o horizonte de uma comunidade a vir, de um corpo que há que dar à comunidade, com a vantagem de não apresentar a estrutura dramática de uma redenção final.

A fechar o volume, temos um conjunto de revisões de livros clássicos (Anatomy of female power: a masculinist dissection of matriarchy, de Chinweizu (1990), por Sara Maia; Metamorphoses: towards a materialist theory of becoming, de Braidotti (2002), por Helena Ferreira; Undoing gender, de Butler (2004), por Rita Himmel e de uma obra concernente a um campo de estudos em desenvolvimento (Estudos Críticos sobre os Animais - Critical Animal Studies) que reúne perspetivas politicamente engajadas sobre as relações humano-animal (Defining critical animal studies: an intersectional social justice approach for liberation, de Nocella II et al (ed.) (2014), por Anabela Santos.

Com os trabalhos acabados de mencionar, a revista Género: contributos para uma compreensão efetiva das mudanças integra conteúdos relevantes para o fortalecimento do conhecimento relativo às questões de género no seio dos estudos culturais lusófonos e para práticas académicas e sociais enformadas por horizontes de justiça social. 